\title{
Differential effects of aging on EEG after baclofen administration
}

\author{
FU Yu ${ }^{1 *}$, CUI JunHui ${ }^{1} \&$ MA Yuan $\mathrm{Ye}^{2}$ \\ ${ }^{1}$ Department of Electronic Engineering, Information School, Yunnan University, Kunming 650091, China; \\ ${ }^{2}$ State Key Laboratory of Brain and Cognitive Science, Kunming Institute of Zoology, \\ Chinese Academy of Sciences, Kunming 650223, China
}

Received July 4, 2010; accepted February 21, 2011

\begin{abstract}
Baclofen is a selective gamma-aminobutyric acid (GABA) type B agonist that may have important medicinal uses, such as in analgesics and drug addiction treatment. In addition, evidence is accumulating that suggests GABAergic-mediated neurotransmission is altered during aging. This study investigated whether baclofen administration $\left(5 \mathrm{mg} \mathrm{kg}^{-1}\right)$ induces differential effects on cortical electrical activity with age. Electroencephalograms (EEGs) were recorded from young (3-4 months) and aged (15-17 months) rats, and both the absolute and relative powers in five frequency bands (delta: $2-4 \mathrm{~Hz}$; theta: 4-8 Hz; alpha: $8-12 \mathrm{~Hz}$; beta: $12-20 \mathrm{~Hz}$; gamma: $20-100 \mathrm{~Hz}$ ) were analyzed. Before administration of baclofen, we found that the EEG relative power in the beta band was higher in the aged than that in the young rats. After administration of baclofen, there was a slower increase in the relative power in the delta band in the aged than that in the young rats. Moreover, there was no significant difference between the two age groups in absolute power in any frequency band. These findings indicate that baclofen treatment appears to differentially modify cortical EEG activity as a function of age. Our data further elucidate the relationship between $\mathrm{GABA}_{\mathrm{B}}$ receptor-mediated neurotransmission and aging.
\end{abstract}

aging, baclofen, EEG, spectra power, rat

Citation: Fu Y, Cui J H, Ma Y Y. Differential effects of aging on EEG after baclofen administration. Sci China Life Sci, 2011, 54: 459-465, doi: $10.1007 / \mathrm{s} 11427-011-4170-1$

In the central nervous system, gamma-aminobutyric acid (GABA) is the major inhibitory neurotransmitter and acts mainly via $\mathrm{GABA}_{\mathrm{A}}$ and $\mathrm{GABA}_{\mathrm{B}}$ receptors. Evidence is accumulating that a number of GABAergic parameters undergo changes during aging. For example, GABA production may decrease in old monkeys [1]. Levels of glutamic acid decarboxylase, an enzyme needed to synthesize GABA, have also been observed to decrease with age [2]. Moreover, both $\mathrm{GABA}_{\mathrm{A}}$ and $\mathrm{GABA}_{\mathrm{B}}$ receptors exhibit some alterations in their subunits or at their binding sites during aging [2-5].

Pentobarbital is a positive allosteric modulator of the $\mathrm{GABA}_{\mathrm{A}}$ receptor that has more pronounced effects on cortical electrical activity in aged rats than those in young rats [6].

*Corresponding author (email: fuyu @ynu.edu.cn)
In addition, muscimol is a $\mathrm{GABA}_{\mathrm{A}}$ agonist, and it greatly inhibits the spontaneous activity of medial vestibular nucleus neurons in aged rats [7]. However, few studies have examined the relationship between the $\mathrm{GABA}_{\mathrm{B}}$ receptor and age-related changes in brain activity. Nevertheless, GABA receptors have been implicated in memory processes [8], and $\mathrm{GABA}_{\mathrm{B}}$ receptor binding is altered in Alzheimer's disease $[9,10]$. Therefore, in the present study, we determined whether aging has an effect on cortical electrical activity that is associated with the $\mathrm{GABA}_{\mathrm{B}}$ receptor.

Baclofen is a selective $\mathrm{GABA}_{\mathrm{B}}$ receptor agonist that can induce some important biological actions, such as antinociception, motor impairment, muscle relaxation and hypothermia. In addition, previous studies have suggested that baclofen reduces ethanol consumption in a dose-dependent manner [11], and the systemic administration of this drug 
induces increases in food intake [12,13].

An electroencephalogram (EEG) is an amplification of electrical activity generated by neurons in the brain. Much evidence suggests that EEGs are a sensitive measure of age-related changes in brain activity following drug administration [14-16]. For example, almitrine injection induced an increase in EEG power in all frequency bands in young rats, but this increase was only observed in the low-frequency range in aged rats. Moreover, raubasine elicited a greater increase in EEG power in the 10-20 Hz frequency range in aged rats than in young rats [15].

In the present study, EEGs were recorded from young and aged rats both before and after baclofen administration. Moreover, both the absolute and relative powers of the EEG frequency bands were calculated and compared between the two groups. This work further elucidates our understanding of $\mathrm{GABA}_{\mathrm{B}}$ receptor-mediated changes in brain activity during aging.

\section{Materials and methods}

\subsection{Animals}

Experiments were performed on 6 young and 6 aged male Sprague-Dawley rats (Animal House Centre, Kunming Medical College, Kunming, China). Young rats were 3-4 months of age with a mean weight of $(345 \pm 8) \mathrm{g}$, and aged animals were 15-17 months of age with a mean weight of $(538 \pm 30) \mathrm{g}$. Animals were housed in individual cages under conditions of a constant temperature of $(23 \pm 1)^{\circ} \mathrm{C}$, stable humidity, and a 12-h light/12-h dark cycle. They had free access to food and water. All experimental and animal care procedures were carried out in accordance with the guidelines for the National Care and Use of Animals and approved by the National Animal Research Authority.

\subsection{Surgeries}

All surgeries were performed after anesthetizing the subject with an intraperitoneal (i.p.) injection of pentobarbital (40 $\mathrm{mg} \mathrm{kg}^{-1}$ dissolved in $0.9 \%$ sodium, $40 \mathrm{mg} \mathrm{mL}^{-1}$; Sigma, St. Louis, MO, USA). After a midline scalp incision, three burr holes were drilled in the skull. A stainless-steel watch screw was placed in contact with the dura through a hole in the skull over the left hemisphere: $3 \mathrm{~mm}$ posterior, $2.5 \mathrm{~mm}$ lateral to bregma [17]. Similarly, a screw in the skull over the left hemisphere served as the reference electrode: $4 \mathrm{~mm}$ anterior, $2 \mathrm{~mm}$ lateral to bregma. Another screw in the skull over the right hemisphere served as the ground electrode: $5 \mathrm{~mm}$ posterior, $2 \mathrm{~mm}$ lateral to bregma. Two or more additional support screws were positioned, and the entire ensemble was affixed to the skull with dental acrylic. All electrodes were attached to male pins that were secured in a rectangular $3 \times 1$ pin array and affixed with dental acrylic. A general penicillin antibiotic was administered by intramuscular (i.m.) injection (50000 units; Harbin Pharmaceutical Group, Harbin, China) immediately after the surgery. Subjects were allowed at least one week to recover after the surgery before EEG recordings were initiated.

\subsection{EEG recordings}

Using custom built equipment [6,18,19], EEG recordings were collected in a sound-attenuating chamber $(40 \mathrm{~cm} \times$ $25 \mathrm{~cm}$ ), which was illuminated by a $12 \mathrm{~V}$ bulb. All electrodes on the rat were connected by a cable to an amplifier and then to a computer. The cable was suspended to allow the rat to move freely. The EEG signals were amplified 25000 times and filtered (bandpass: $0.5-100 \mathrm{~Hz}$; with no 50 $\mathrm{Hz}$ filtering). The amplified EEG signals were digitalized with an analog-to-digital board (biphase, $1000 \mathrm{~Hz}$ ), displayed instantly, and saved to the computer. Every $20 \mathrm{~min}$ of recording was automatically saved and consisted of 100 segments of data. Each segment lasted $2 \mathrm{~s}$ and was collected every $10 \mathrm{~s}$

After habituating the animals to the recording conditions, baseline recordings (40 $\mathrm{min})$ were acquired. Subsequently, we injected baclofen $\left(5 \mathrm{mg} \mathrm{kg}^{-1}\right.$, i.p.; dissolved in $0.1 \mathrm{~mol} \mathrm{~L}^{-1}$ $\mathrm{HCl}$ [20], $5 \mathrm{mg} \mathrm{mL}^{-1}$; Ningbo Team Pharmaceutical Factory, Ningbo, China) and recorded EEG activity for 180 $\min$.

\subsection{Data analyses and statistics}

As previously described [6], EEG signals were examined by off-line analysis and spectral analysis was performed using MATLAB (Version 6.5; Math Works, Natick, MA, USA). EEG data recorded over a 20 -min period were separated into 100 segments, and each segment was composed of 2000 sample points, of which the first 1024 points were defined as an epoch. Each epoch without artifacts was filtered for the following EEG frequency bands: (1) delta 2-4 $\mathrm{Hz}$; (2) theta 4-8 Hz; (3) alpha 8-12 Hz; (4) beta 12-20 Hz; and (5) gamma 20-100 Hz. For each frequency band, the absolute power of every epoch was calculated using the formula $\Sigma x^{2} / 1024$, and the average power over 100 epochs served as the calculated power over the 20 -min period. The relative power was calculated as the percentage of the absolute power of any frequency band relative to the total absolute power of all frequency bands. In addition, because of pronounced interindividual differences, the normalized power was adopted and calculated as $\left(P_{1}-P_{0}\right) / P_{0} \times 100 \%$, where $P_{0}$ denotes the power for baseline recordings and $P_{1}$ denotes the power for post-drug recordings. We have previously shown that normalized power is a reliable parameter, even when the baseline EEG is not stable $[6,18,19]$.

A one-sample Kolmogorov-Smirnov test was performed to determine whether the data were normally distributed, using SPSS (Version 10.0; SPSS, Chicago, IL, USA). Be- 
cause the data had a normal distribution $(P>0.05)$, differences between groups were assessed using analysis of variance (ANOVA) with repeated measures or one-way ANOVA where appropriate. All results are expressed as mean \pm SE. A level of $P<0.05$ was considered as significant and $P<0.01$ as highly significant.

\section{Results}

Before the injection of baclofen, cortical EEG recordings were performed in young and aged rats (Figure 1). There was no significant difference in the absolute power in any frequency band between the two age groups $(F(1,11)=$ $0.039,0.000,0.027,2.403$ and $2.379 ; P=0.848,0.984,0.873$, 0.152 and 0.154 for the delta, theta, alpha, beta and gamma bands, respectively) (Figure 2A). In contrast, the relative power in the beta band was significantly higher in the aged rats compared with the young rats $(F(1,11)=26.831, P<$ $0.001)$. There was no significant difference in the relative powers in the remaining frequency bands between the two groups $(F(1,11)=0.172,0.847,0.040$ and $0.895 ; P=$ $0.687,0.379,0.846$ and 0.367 for the delta, theta, alpha and gamma bands, respectively) (Figure 3A).

Combined ANOVA showed that baclofen administration significantly increased the normalized absolute power in all frequency bands $(F(9,90)=11.167,6.150,5.767$ and 5.994 for the delta, theta, alpha and beta bands, respectively; $P<$ 0.001 for all bands) except the gamma band $(F(9,90)=$ 1.884, $P=0.064$ ) (Figure $2 \mathrm{~B}-\mathrm{F}$ ). For the normalized relative power, combined ANOVA showed an increase in the delta band $(F(9,90)=6.752, P<0.001)$, a decrease in theta and alpha bands $(F(9,90)=6.556$ and $3.227 ; P<0.001$ and 0.01 for the theta and alpha bands, respectively), an initial increase and then a decrease in the gamma band $(F(9,90)=$ $6.601, P<0.001)$, and no significant change in the beta band $(F(9,90)=0.973, P=0.468)$ (Figure 3B-F).

On the other hand, combined ANOVA found no significant interaction between age and time in the normalized absolute power of any frequency band $(F(9,90)=1.214$, $0.274,0.976,0.973$ and $1.493 ; P=0.296,0.980,0.465,0.468$ and 0.163 for the delta, theta, alpha, beta and gamma bands, respectively). For normalized relative power, however, a significant interaction between age and time was observed in both the delta and theta bands $(F(9,90)=2.207$ and 3.824; $P<0.05$ and 0.001 for the delta and theta bands, respectively). For the delta band, the two groups exhibited different powers at $20 \mathrm{~min}$, with the aged rats showing a slower increase than the young rats $(F(1,11)=6.491, P<$ 0.05 ) (Figure $3 \mathrm{~B}$ ). For the theta band, the aged rats displayed a trend towards a slower decrease in its power at 20 $\min (F(1,11)=3.769, P=0.081)$ and a faster decrease in its power at $60 \mathrm{~min}$ and $80 \mathrm{~min}(F(1,11)=4.214$ and 3.623; $P=$ 0.067 and 0.086 , for $60 \mathrm{~min}$ and $80 \mathrm{~min}$, respectively) (Figure $3 \mathrm{C})$.

\section{Discussion}

In this study, we investigated cortical changes in EEG activity before and after injection of baclofen in young and aged rats. Before the injection, the EEG absolute power in five frequency bands was not significantly different between the two groups, but the relative power in the beta band was significantly higher in the aged rats. After the baclofen administration, the absolute power in all frequency bands except the gamma band increased in animals of both ages. The relative power in the theta and alpha bands decreased, and the relative power in the gamma band initially increased and then decreased in both groups. Moreover, the relative power in the delta band increased in the two groups, but more slowly in the aged rats. Our data indicate that baclofen administration induces differential changes in the cortical electrical activities of young and aged animals.

We observed differences in the EEG frequency bands in their relative powers but not in their absolute powers. The appropriateness of analyzing EEGs by absolute or relative power is still under debate. Some research groups have re-
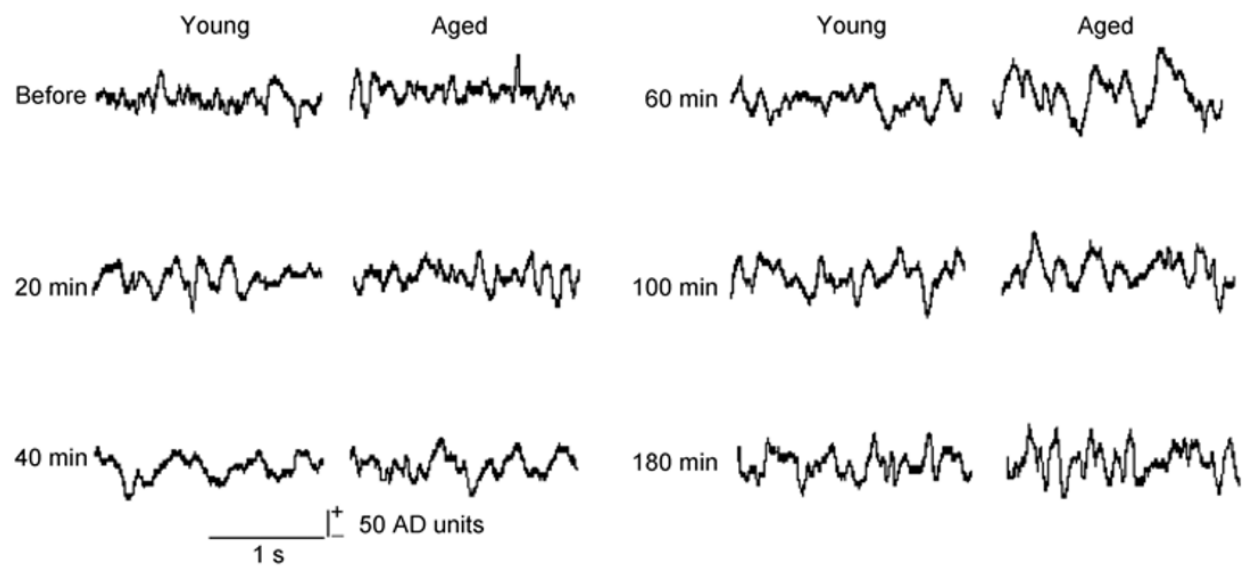

Figure 1 Effects of baclofen $\left(5 \mathrm{mg} \mathrm{kg}^{-1}\right.$, i.p.) on the baseline EEG waves in young and aged rats. 

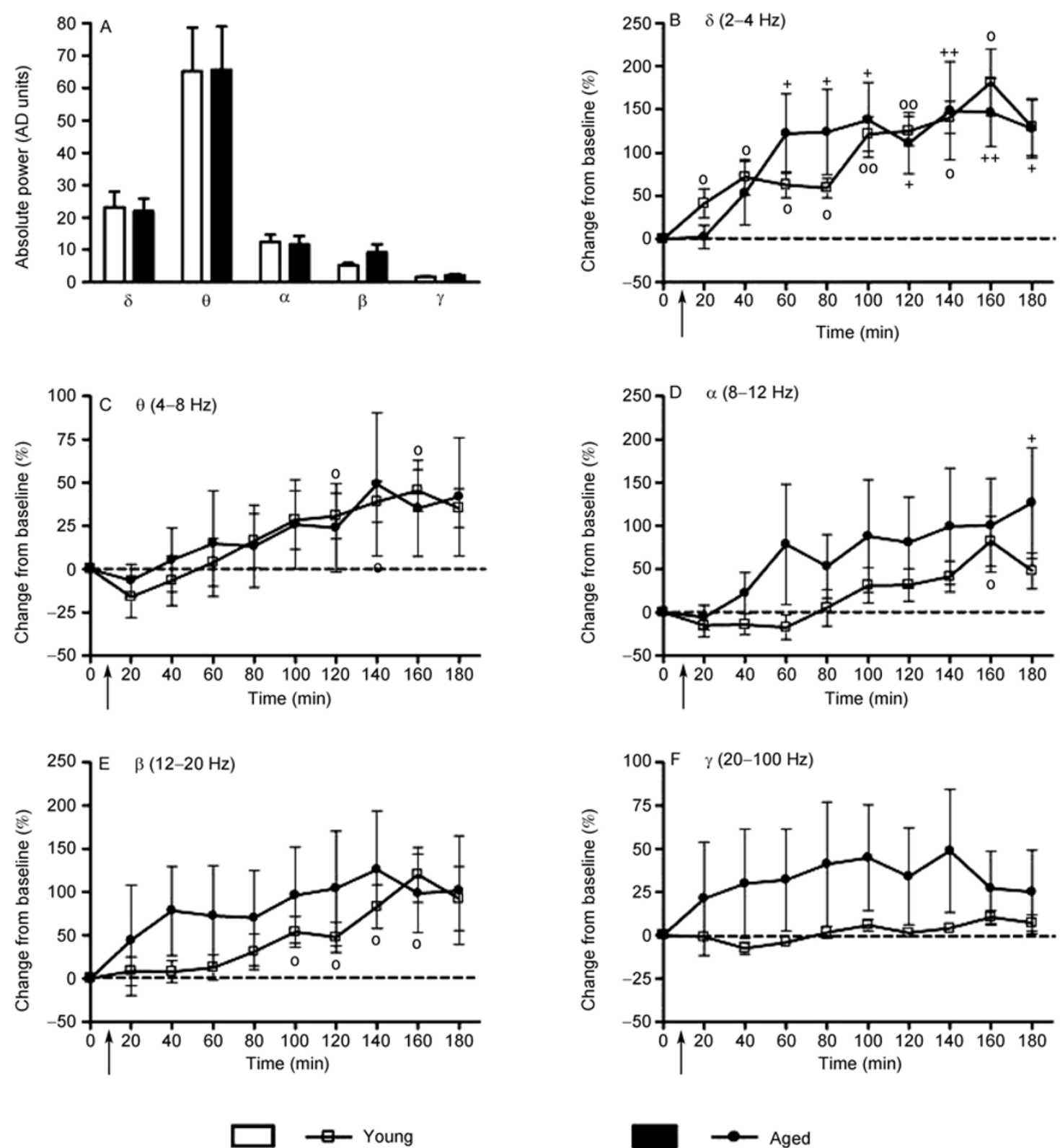

Figure 2 EEG changes in the absolute powers in five frequency bands (delta: 2-4 Hz; theta: 4-8 Hz; alpha: 8-12 Hz; beta: 12-20 Hz; gamma: 20-100 Hz) in young and aged rats before and after injection of baclofen. A, The absolute power before the injection of baclofen. B-F, EEG changes in normalized absolute power after the injection of baclofen. The dashed line indicates the baseline EEG power and the black arrow shows the time of drug injection. ${ }^{\circ} P<0.05$ and ${ }^{\circ 0} P<0.01$ compared with the baseline for the young group; ${ }^{+} P<0.05$ and ${ }^{++} P<0.01$ compared with the baseline for the aged group.

ported both absolute and relative power values in developmental studies $[21,22]$. However, many studies suggest that the absolute power is not suitable for use in developmental studies because of changes in bone thickness, skull resistance and impedance with age [23]. In addition, John et al. [24] indicated that the relative power has better test-retest reliability than absolute power. Taken together, the present study supports the notion that, as concluded by Clarke et al. [21], relative power is more sensitive than the absolute power to changes in the EEG frequency bands with age. However, because relative power is derived from the total absolute power, this issue requires further investigation.

In accord with previous results described in humans [25,26], the basal EEG relative power showed an obvious increase in the beta band in the aged rats. For example, Knott and Harr [26] observed a significant increase in the relative beta power with increasing age (from 18-39 to 64-81 years). Nevertheless, other data conflict with this age-related change in the EEG during the awake state. Braida and colleagues [14] reported an increase in the relative power in the delta band and a decrease in the alpha and beta bands in aged rats (27-30 months) compared with 

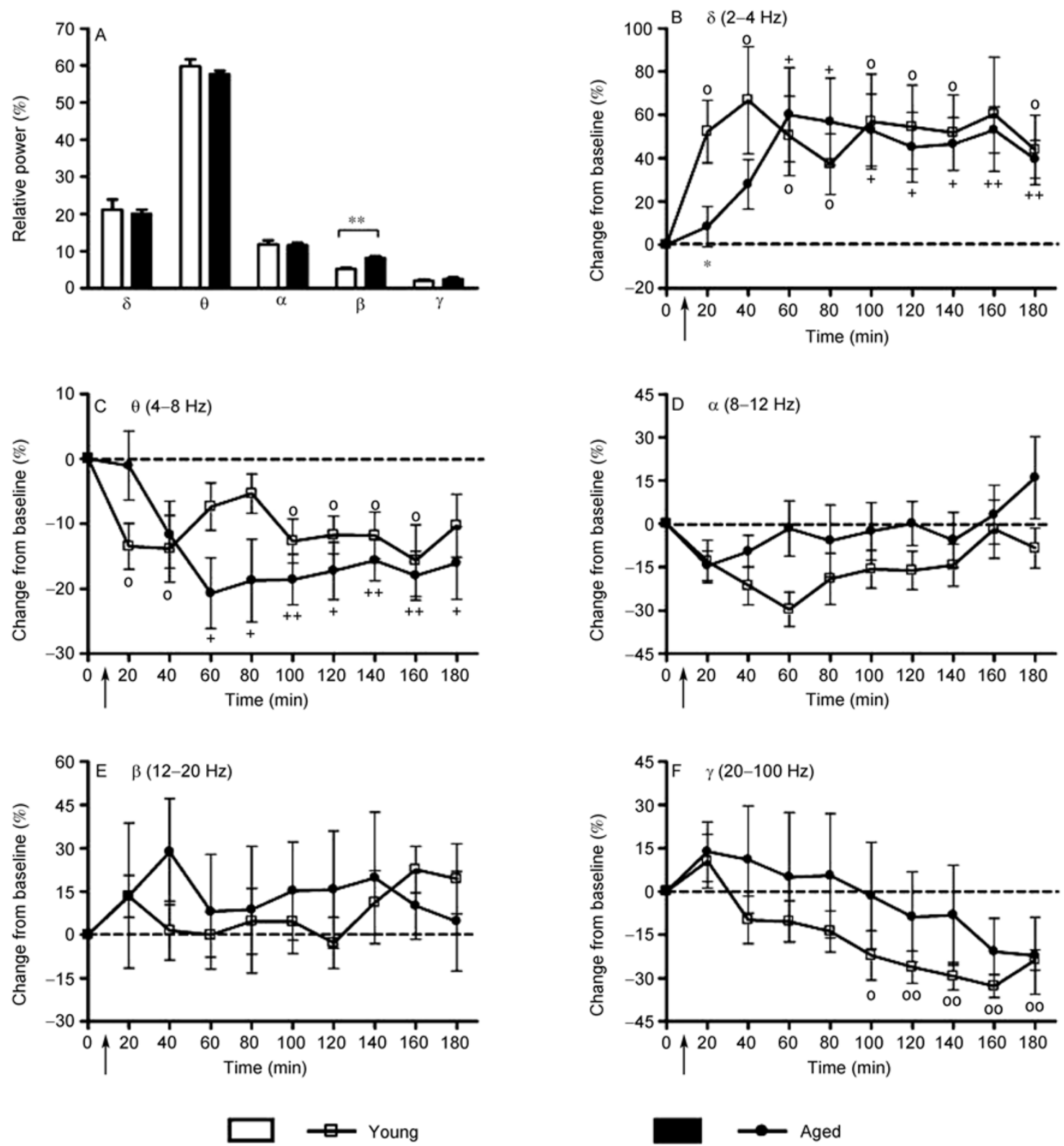

Figure 3 EEG changes in the relative powers in five frequency bands in young and aged rats before and after injection of baclofen. A, The relative power before the injection of baclofen. B-F, EEG changes in the normalized relative power after the injection of baclofen. The dashed line indicates the baseline EEG power and the black arrow shows the time of drug injection. ${ }^{\circ} P<0.05$ and ${ }^{\circ o} P<0.01$ compared with the baseline for the young group; ${ }^{+} P<0.05$ and ${ }^{++} P<0.01$ compared with the baseline for the aged group.

those young rats (4-6 months). These differences may depend on experimental variables, such as the age of the subjects.

Compared with its effects in young rats, baclofen administration induced a different change in cortical electrical activity in aged rats, reflected by a slower increase of EEG activity in the delta frequency band at $20 \mathrm{~min}$ after drug administration. The delta rhythm is associated with the broad functional process of cortical inhibition [27]. Typically, this slow wave band can be observed in the deepest stages of sleep and is strongly reduced in the waking state.
Recent studies, however, suggest a reconsideration of the functional roles of EEG frequency bands. For example, when the delta rhythm appears in wakefulness, it can be considered as a marker of brain damage or pathological conditions resulting from neurological damage or psychiatric disease [28-30]. Based on these data, we hypothesize that the age-related EEG changes in the delta band induced by baclofen may indicate that some pathological changes occurred during aging.

A previous study has indicated that slow oscillations $(0.5-4.0 \mathrm{~Hz})$ elicited from the cortex depend on synaptically 
induced hyperpolarization of thalamocortical cells [31]. Accordingly, Steriade et al. [32] proposed that the potential effects of the corticothalamic input on delta potentials results from the engagement of two GABAergic thalamic cell classes, namely reticular and local-circuit neurons. Thus, it is reasonable that baclofen, as a selective $\mathrm{GABA}_{B}$ agonist, may induce different EEG activity in the delta band $(2.0-4.0 \mathrm{~Hz})$ of aged rats, which may be mediated by alterations in $\mathrm{GABA}_{\mathrm{B}}$ receptor-mediated neurotransmission with age.

There are only a few studies of age-related changes in brain activity that investigated the role of the $\mathrm{GABA}_{B}$ receptor. Him et al. showed that baclofen tended to induce a greater inhibitory effect on spontaneous activity in medial vestibular nucleus slices from aged rats than those from young rats [7]. Billard et al. showed that the slower $\mathrm{GABA}_{\mathrm{B}}$-mediated postsynaptic inhibition of CA1 pyramidal cells was decreased in some strains of aged rats [33]. Thus, baclofen may modify cortical electrical activity in an age dependent manner.

In addition, $\mathrm{GABA}_{\mathrm{B}}$ receptor binding in some primary regions of the inferior colliculus was significantly lower in 26-month-old rats than in 3-month-old rats [5]. Other investigations have been performed on age-related changes in the whole GABAergic system, such as the loss of GABA neurons [34], decreased levels of the enzyme needed to synthesize GABA [2], and some alterations in $\mathrm{GABA}_{\mathrm{A}}$ subunits and in the combination of the subunits [2,4]. Therefore, the present data support the current hypothesis by suggesting a reduction in GABA-mediated inhibition in the senescent brain.

In summary, the present study shows that baclofen treatment may differentially modify cortical electrical activity as a function of age. These data further elucidate the changes in $\mathrm{GABA}_{\mathrm{B}}$ receptor-mediated neurotransmission during aging.

We thank Wang Jianhong, Zeng Tao, Tian Shaohua and Sun Huaying (Kunming Institute of Zoology, Chinese Academy of Sciences) for their help during the experiments. This work was supported by grants from the Training Program for Young Backbone Teachers of Yunnan University, the Research Foundation of Yunnan University (Grant No. 2008YB007), the Science Foundation of the Education Department of Yunnan (Grant No. 09Y0034), the Special Fund of the "211" Third Phase Project of Yunnan University (Grant No. 21134018) and the National College Student Innovation Experiment Program (Grant No. 101067312).

1 Leventhal A G, Wang Y, Pu M, et al. GABA and its agonists improved visual cortical function in senescent monkeys. Science, 2003, 300: 812-815

2 Gutierrez A, Khan Z U, Morris S J, et al. Age-related decrease of $\mathrm{GABA}_{\mathrm{A}}$ receptor subunits and glutamic acid decarboxylase in the rat inferior colliculus. J Neurosci, 1994, 14: 7469-7477

3 Turgeon S M, Albin R L. GABA ${ }_{B}$ binding sites in early adult and aging rat brain. Neurobiol Aging, 1994, 15: 705-711

4 Mhatre M C, Ticku M K. Aging related alterations in $\mathrm{GABA}_{\mathrm{A}}$ receptor subunit mRNA levels in Fischer rats. Brain Res Mol Brain Res,
1992, 14: 71-78

5 Milbrandt J C, Albin R L, Caspary D M. Age-related decrease in $\mathrm{GABA}_{\mathrm{B}}$ receptor binding in the Fischer 344 rat inferior colliculus. Neurobiol Aging, 1994, 15: 699-703

6 Fu Y, Guo L, Zhang J, et al. Differential effects of ageing on the EEG during pentobarbital and ketamine anaesthesia. Eur J Anaesthesiol, 2008, 25:826-833

7 Him A, Johnston A R, Yau J L, et al. Tonic activity and GABA responsiveness of medial vestibular nucleus neurons in aged rats. Neuroreport, 2001, 12: 3965-3968

8 Brioni J D. Role of GABA during the multiple consolidation of memory. Drug Develop Res, 1993, 28: 3-27

9 Chu D C, Penney J B, Young A B. Quantitative autoradiography of hippocampal $\mathrm{GABA}_{B}$ and $\mathrm{GABA}_{\mathrm{A}}$ receptor changes in Alzheimer's disease. Neurosci Lett, 1987, 82: 246-252

10 Chu D C, Penney J B, Young A B. Cortical GABA $A_{B}$ and $\mathrm{GABA}_{\mathrm{A}}$ receptors in Alzheimer's disease: a quantitative autoradiographic study. Neurology, 1987, 37: 1454-1459

11 Colombo G, Agabio R, Carai M A, et al. Ability of baclofen in reducing alcohol intake and withdrawal severity: I-Preclinical evidence. Alcohol Clin Exp Res, 2000, 24: 58-66

12 Ebenezer I S. The effect of intracerebroventricular administration of baclofen on food intake in rats. Neuroreport, 1990, 1: 73-76

13 Ebenezer I S, Pringle A K. The effect of systemic administration of baclofen on food intake in rats. Neuropharmacology, 1992, 31:3942

14 Braida D, Ottonello F, Sala M. Eptastigmine restores the aged rat's normal cortical spectral power pattern. Pharmacol Res, 2000, 42: 495-500

15 Sebban C, Tesolin B, Coulomb B, et al. Comparative effects of almitrine and raubasine, singly and in combination, on electroencephalographic activity in young and old rats. Exp Gerontol, 1989, 24: 11-24

16 Schultz A, Grouven U, Zander I, et al. Age-related effects in the EEG during propofol anaesthesia. Acta Anaesthesiol Scand, 2004, 48: 27-34

17 Paxinos, G. and Watson, C. The rat brain in stereotaxic coordinates. San Diego (CA): Academic Press. 2005

18 Liu N, Liu Y, Fan Y, et al. EEG activities in the orbitofrontal cortex and dorsolateral prefrontal cortex during the development of morphine dependence, tolerance and withdrawal in rhesus monkeys. Brain Res, 2005, 1053: 137-145

19 Sun N, Li Y, Tian S, et al. Dynamic changes in orbitofrontal neuronal activity in rats during opiate administration and withdrawal. Neuroscience, 2006, 138: 77-82

20 Kishitake M, Yamanouchi K. Facilitatory effects of WAY-100635, a 5-HT1A receptor antagonist, on lordosis in female rats. Neurosci Lett, 2004, 371: 147-151

21 Clarke A R, Barry R J, McCarthy R, et al. Age and sex effects in the EEG: differences in two subtypes of attention-deficit/hyperactivity disorder. Clin Neurophysiol, 2001, 112: 815-826

22 Gasser T, Verleger R, Bacher P, et al. Development of the EEG of school-age children and adolescents. I. Analysis of band power. Electroencephalogr Clin Neurophysiol, 1988, 69: 91-99

23 Benninger C, Matthis P, Scheffner D. EEG development of healthy boys and girls. Results of a longitudinal study. Electroencephalogr Clin Neurophysiol, 1984, 57: 1-12

24 John E R, Ahn H, Prichep L, et al. Developmental equations for the electroencephalogram. Science, 1980, 210: 1255-1258

25 Duffy F H, McAnulty G B, Albert M S. The pattern of age-related differences in electrophysiological activity of healthy males and females. Neurobiol Aging, 1993, 14: 73-84

26 Knott V J, Harr A. Assessing the topographic EEG changes associated with aging and acute/long-term effects of smoking. Neuropsychobiology, 1996, 33: 210-222

27 Pfurtscheller G, Stancak A Jr, Neuper C. Event-related synchronization (ERS) in the alpha band-an electrophysiological correlate of cortical idling: a review. Int J Psychophysiol, 1996, 24: 39-46

28 Babiloni C, Frisoni G, Steriade M, et al. Frontal white matter volume 
and delta EEG sources negatively correlate in awake subjects with mild cognitive impairment and Alzheimer's disease. Clin Neurophysiol, 2006, 117: 1113-1129

29 Penolazzi B, Spironelli C, Angrilli A. Delta EEG activity as a marker of dysfunctional linguistic processing in developmental dyslexia. Psychophysiology, 2008, 45: 1025-1033

30 Spironelli C, Angrilli A. EEG delta band as a marker of brain damage in aphasic patients after recovery of language. Neuropsychologia, 2009, 47: 988-994

31 Dossi R C, Nunez A, Steriade M. Electrophysiology of a slow (0.5-4 $\mathrm{Hz}$ ) intrinsic oscillation of cat thalamocortical neurones in vivo. $\mathrm{J}$ Physiol, 1992, 447: 215-234
32 Steriade M, Dossi R C, Nunez A. Network modulation of a slow intrinsic oscillation of cat thalamocortical neurons implicated in sleep delta waves: cortically induced synchronization and brainstem cholinergic suppression. J Neurosci, 1991, 11: 3200-3217

33 Billard J M, Lamour Y, Dutar P. Decreased monosynaptic GABA $\mathrm{B}^{-}$ mediated inhibitory postsynaptic potentials in hippocampal CA1 pyramidal cells in the aged rat: pharmacological characterization and possible mechanisms. J Neurophysiol, 1995, 74: 539-546

34 Caspary D M, Raza A, Lawhorn Armour B A, et al. Immunocytochemical and neurochemical evidence for age-related loss of GABA in the inferior colliculus: implications for neural presbycusis. J Neurosci, 1990, 10: 2363-2372

Open Access This article is distributed under the terms of the Creative Commons Attribution License which permits any use, distribution, and reproduction in any medium, provided the original author(s) and source are credited. 